Article

\title{
Low Body Mass Index as a Predictive Factor for Postoperative Infectious Complications after Ureterorenoscopic Lithotripsy
}

\author{
Kensaku Seike ${ }^{1}$, Takashi Ishida ${ }^{2}$, Tomoki Taniguchi ${ }^{1}{ }^{\mathbb{D}}$, Shota Fujimoto ${ }^{3}$, Daiki Kato ${ }^{4} \mathbb{D}$, Manabu Takai $^{4}$, \\ Koji Iinuma ${ }^{4}$, Keita Nakane ${ }^{4}$, Hiromi Uno ${ }^{1}$, Masayoshi Tamaki ${ }^{2}$, Hisao Komeda ${ }^{2}$ and Takuya Koie ${ }^{4, *}$ (DD \\ 1 Department of Urology, Chuno Kosei Hospital, Seki 5013802, Japan; k-seike@chuno.gfkosei.or.jp (K.S.); \\ t-tani@chuno.gfkosei.or.jp (T.T.); h-uno@chuno.gfkosei.or.jp (H.U.) \\ 2 Department of Urology, Gifu Municipal Hospital, Gifu 5008513, Japan; justaskaxis@gmail.com (T.I.); \\ mtamaki@gmhosp.gifu.gifu.jp (M.T.); hkome@gmhosp.gifu.gifu.jp (H.K.) \\ 3 Department of Urology, Ogaki Municipal Hospital, Ogaki 5038502, Japan; uro2@omh.ogaki.gifu.jp \\ 4 Department of Urology, Gifu University Graduate School of Medicine, Gifu 5011194, Japan; \\ andreas7@gifu-u.ac.jp (D.K.); takai_mb@gifu-u.ac.jp (M.T.); kiinuma@gifu-u.ac.jp (K.I.); \\ keitaco@gifu-u.ac.jp (K.N.) \\ * Correspondence: goodwin@gifu-u.ac.jp; Tel.: +81-582-306-000
}

check for updates

Citation: Seike, K.; Ishida, T.; Taniguchi, T.; Fujimoto, S.; Kato, D.; Takai, M.; Iinuma, K.; Nakane, K.; Uno, H.; Tamaki, M.; et al. Low Body Mass Index as a Predictive Factor for Postoperative Infectious Complications after Ureterorenoscopic Lithotripsy. Medicina 2021, 57, 1100. https:// doi.org/10.3390/medicina57101100

Academic Editor: Michal Nowicki

Received: 27 September 2021

Accepted: 11 October 2021

Published: 13 October 2021

Publisher's Note: MDPI stays neutral with regard to jurisdictional claims in published maps and institutional affiliations.

Copyright: (C) 2021 by the authors. Licensee MDPI, Basel, Switzerland. This article is an open access article distributed under the terms and conditions of the Creative Commons Attribution (CC BY) license (https:/ / creativecommons.org/licenses/by/ $4.0 /)$.

\begin{abstract}
Background and Objectives: In this study, we aimed to evaluate predictive factors of postoperative fever (POF) after ureterorenoscopic lithotripsy (URSL). Materials and Methods: A total of 594 consecutive patients who underwent URSL for urinary stone disease at Gifu Municipal Hospital and Chuno Kosei Hospital between April 2016 and January 2021 were enrolled in this study. In all patients, antibiotics were routinely administered intraoperatively and the next day after surgery. We used rigid and/or flexible ureterorenoscopes depending on the stone location for URSL. Stones were fragmented using a holmium: YAG laser. The fragments of the stone were manually removed as much as possible using a stone basket catheter. A ureteral stent was placed at the end of the surgery in all cases. Results: The median age and body mass index (BMI) in all patients were 62 years and $23.8 \mathrm{~kg} / \mathrm{m}^{2}$, respectively. The median operation duration was $52 \mathrm{~min}$. The most common URSL-related complication was POF in 28 (4.7\%) patients. In these patients, the rates of antibiotic administration and ureteral stent insertion before surgery were significantly higher than in those without POF. In multivariate analysis, BMI was associated with POF after URSL. There were no significant differences in predicting POF after surgery in patients who had bacteriuria or received antibiotics before surgery. Conclusions: A low BMI was significantly associated with POF after URS or URSL.
\end{abstract}

Keywords: stone disease; ureteroscopy; ureterorenoscopic lithotripsy; infectious complication; body mass index

\section{Introduction}

Urinary stones are one of the most common benign urologic diseases, with a lifetime incidence of approximately 10\% [1], and a common cause of morbidity and deterioration of quality of life worldwide [2]. In Japan, the incidence of lower urinary tract stones has gradually increased from 4.7/100,000 in 1965 to 9.1/100,000 in 2005 [3]. Likewise, the estimated age-standardized annual incidence of upper urinary tract stones was 54.2/100,000 in 1965 and 114.3/100,000 in 2005 [4].

The management of urolithiasis has dramatically changed over the last three decades [5]. Minimally invasive techniques such as ureterorenoscopic lithotripsy (URSL), shockwave lithotripsy (SWL), and percutaneous nephrolithotomy (PNL) are the standard treatment modalities based on patient preference, symptoms, stone location, and stone size [6]. Recently, URSL has been accepted as the first-line treatment choice for ureter and renal stones, with better stone-free rates than SWL and lower complication rates than PNL [7]. 
However, postoperative complications occur in $2.5-6.7 \%$ patients after ureterorenoscopy (URS) [8,9].

Postoperative fever (POF) is the most common complication of ureteroscopic holmium laser lithotripsy, with an incidence rate of 2-28\% [8-10]. In addition, POF is potentially serious because it may progress to urosepsis, leading to death [11]. Although predictive factors that may be associated with infectious complications in PNL and SWL have been evaluated, only a limited number of studies have identified predictive factors for POF after URSL $[12,13]$. Furthermore, there is no consensus on the predictive factors that may lead to infectious complications after URS. Therefore, this study aimed to evaluate the predictive factors of POF after URSL.

\section{Materials and Methods}

\subsection{Patients}

The study protocol was approved by the Institutional Review Board of Chuno Kosei Hospital (number: R3-1) and Gifu Municipal Hospital (number: 707). We retrospectively reviewed the data of 630 consecutive patients who underwent URSL for urinary stone disease at Gifu Municipal Hospital and Chuno Kosei Hospital between April 2016 and January 2021. Preoperative data included age, gender, body mass index (BMI), preoperative bacteriuria, history of diabetes mellitus or hypertension, preoperative antibiotic use, and laboratory parameters related to systemic inflammation. The location (ureter or kidney), size, multiplicity of the stones, preoperative ureteral stent insertion, and operation duration were also evaluated. The comorbidities of the enrolled patients using Charlson comorbidity index or the American Society of Anesthesiologists physical status were not evaluated in this retrospective study. Patients with fever $\left(>38^{\circ} \mathrm{C}\right)$ persisting for $48 \mathrm{~h}$ after URSL were considered to have POF.

\subsection{URSL Technique}

The procedure was performed under general or spinal anesthesia with the patient in the lithotomy position. All URSLs were performed by three expert surgeons (K.S., T.T., and S.F.). In all patients, antibiotics (usually cefazolin) were routinely administered intraoperatively and the next day after surgery. We used a 6.5/7.5-Fr rigid URS (r-URS) (Richard Wolf Medical Instruments Cooperation, Knittlingen, Germany) or flexible URSs (f-URS), including 7.5-Fr Flex-X2 ${ }^{\mathrm{TM}}$ (Karl Storz, Tuttlingen, Germany), 9.9-Fr Cobra-M ${ }^{\mathrm{TM}}$ (Richard Wolf Medical Instruments Corporation, Knittlingen, Germany), 8.5/9.9-Fr URFtype V (Olympus, Tokyo, Japan), or 4.9/7.95-Fr URF-P7 (Olympus, Tokyo, Japan).

The first step was to observe the ureter using a r-URS after the insertion of a safety guidewire. URSL was performed using the r-URS for direct access to the target stone. If the target stone could not be observed using the r-URS, an 11/13-12/14-Fr Navigator ${ }^{\mathrm{TM}}$ (Boston Scientific, Boston, MA, USA) or 11/13-12/14-Fr Uropass ${ }^{\circledR}$ (Olympus, Tokyo, Japan) was inserted into the ureter for ureteral access. Then, a f-URS was inserted into the ureter and stones were fragmented using holmium:YAG-Laser (Lumenis, Versa Pulse Select $80 \mathrm{~W}$, Yokneam, Israel) and a 200- $\mu \mathrm{m}$ laser fiber with an energy of $0.5-1.0 \mathrm{~J}$ and a rate of 5-10 Hz. The SAPS ${ }^{\text {TM }}$ CF irrigation system (Boston Scientific, Marlborough, MA, USA) was used to avoid prolonged high-pressure irrigation. The fragments of the stone were picked out as much as possible using a 2.2-Fr NCircle ${ }^{\circledR}$ (COOK, Bloomington, IL, USA), 1.9-Fr. ZeroTip ${ }^{\mathrm{TM}}$ (Boston Scientific, Marlborough, MA, USA), or 1.9-Fr Flex Catch (Olympus, Tokyo, Japan).

A 4.8- or 6-Fr ureteral stent was placed at the end of the surgery in all cases. The ureteral stent was removed 1-2 weeks after URSL.

\subsection{Statistical Analysis}

The primary endpoint was to determine the predictive factors for POF after URS. Data were analyzed using SPSS software (version 24.0; IBM Corp., Armonk, NY, USA). Continuous and categorical variables were compared using the Kruskal-Wallis test. Multivariate 
logistic regression analysis was performed to evaluate the predictors of POF after URSL. Two-sided $p$-values were calculated, and the significance level was set at $p<0.05$.

\section{Results}

A total of 594 patients were enrolled in the study. We excluded 36 patients, including 20 patients with bilateral stones who underwent bilateral URSL with one-step surgery and 16 patients with missing data. The median age and BMI in all patients were 62 years (interquartile range [IQR], $50.3-71$ years) and $23.8 \mathrm{~kg} / \mathrm{m}^{2}$ (IQR, $\left.21.3-26.6 \mathrm{~kg} / \mathrm{m}^{2}\right)$, respectively. The median operation duration was $52 \mathrm{~min}$ (IQR, 35-77 min). The most common URSL-related complication was POF in $28(4.7 \%)$ patients. Of these patients, two $(0.3 \%)$ patients developed sepsis. Subsequently, the surgery-related complications were ureteral injury in eight $(1.3 \%)$ patients, post-dural puncture headache in six $(1.0 \%)$ patients, and hypotension in one $(0.2 \%)$ patient. The commonly reported complications not related to URSL were sinus tachycardia in one $(0.2 \%)$ patient, arteriosclerosis obliterans in one $(0.2 \%)$ patient, and transient ischemic attack in one $(0.2 \%)$ patient.

The demographic data of patients who were classified into two groups according to POF after URSL are listed in Table 1. In patients with POF after URSL, the rates of antibiotic administration and ureteral stent insertion before surgery were significantly higher than in those without POF.

Table 1. Comparison of perioperative covariates and outcomes in patients who had postoperative fever after ureteroscopic lithotripsy or not.

\begin{tabular}{|c|c|c|c|}
\hline Covariates & Patients without POF $(n=559)$ & Patients with POF $(n=35)$ & $p$ Value \\
\hline $\begin{array}{c}\text { Age } \\
\text { (years, median, IQR) }\end{array}$ & $61(50-70)$ & $71(58-81)$ & 0.003 \\
\hline \multicolumn{4}{|l|}{ Gender (number, \%) } \\
\hline Male & $370(66.2)$ & $13(37.1)$ & \multirow{2}{*}{0.001} \\
\hline Female & $189(33.8)$ & $22(62.9)$ & \\
\hline Body mass Index & 23.9 & 21.2 & \multirow{2}{*}{0.002} \\
\hline$\left(\mathrm{kg} / \mathrm{m}^{2}\right.$, median, IQR $)$ & $(21.5-26.8)$ & $(19.0-24.3)$ & \\
\hline \multicolumn{4}{|l|}{ Bacteriuria (number, \%) } \\
\hline Negative & $131(23.4)$ & $4(20.0)$ & \multirow{3}{*}{0.473} \\
\hline Positive & $145(26.0)$ & $21(51.4)$ & \\
\hline Unknown & $283(50.6)$ & $10(28.6)$ & \\
\hline Antibiotics use before surgery (number, $\%$ ) & $33(5.9)$ & $7(20)$ & $<0.001$ \\
\hline Diabetes Mellitus (number, \%) & $79(14.1)$ & $8(22.9)$ & 0.157 \\
\hline Hypertension (number, \%) & $224(40.1)$ & $10(28.6)$ & 0.177 \\
\hline \multicolumn{4}{|l|}{ Stone location (number, \%) } \\
\hline Kidney & $58(10.4)$ & $8(22.9)$ & \multirow[t]{2}{*}{0.023} \\
\hline Ureter & $501(89.6)$ & $27(72.1)$ & \\
\hline Stone size & 9.7 & 10.0 & \multirow{2}{*}{0.229} \\
\hline (mm, median, IQR) & $(7.0-12.0)$ & $(7.3-14.9)$ & \\
\hline \multicolumn{4}{|l|}{ Number of stones } \\
\hline 1 & $443(75.7)$ & $24(68.6)$ & \multirow[t]{2}{*}{0.345} \\
\hline$\geq 2$ & $136(24.3)$ & $11(31.4)$ & \\
\hline $\begin{array}{l}\text { Indwelling of ureter stent before surgery } \\
\text { (number, \%) }\end{array}$ & $154(27.5)$ & $20(57.1)$ & $<0.001$ \\
\hline \multicolumn{4}{|l|}{ Initial laboratory data } \\
\hline Leucocyte count & 6290 & 6400 & \multirow[b]{2}{*}{0.760} \\
\hline$(/ \mu \mathrm{L}$, median, $\mathrm{IQR})$ & $(5105-7630)$ & $(5050-7425)$ & \\
\hline $\begin{array}{l}\text { Platelet count } \\
\left(\times 10^{2}\right.\end{array}$ & 23.5 & 22.9 & \multirow{2}{*}{0.276} \\
\hline $\begin{array}{c}\left(\times 10^{2} / \mu \mathrm{L}, \text { median, IQR }\right) \\
\mathrm{CRP}\end{array}$ & $\begin{array}{c}(19.8-27.8) \\
0.18\end{array}$ & $\begin{array}{c}(16.7-28.0) \\
0.57\end{array}$ & \\
\hline (mg/dL, median, IQR) & $(0.05-0.67)$ & $(0.01-1.90)$ & 0.017 \\
\hline Operation duration (minutes, median, & $\begin{array}{c}52 \\
(35-758)\end{array}$ & 66 & 0.140 \\
\hline Residual stone (number, \%) & $58(10.4)$ & $3(8.6)$ & 0.733 \\
\hline
\end{tabular}

POF, postoperative fever; IQR, interquartile range; CRP, C-reactive protein.

In multivariate analysis, BMI was associated with POF after URSL (Table 2). The incidence of POF after surgery was not significantly different between patients with bacteriuria and those who received antibiotics before surgery. 
Table 2. Multivariate logistic regression test according to postoperative fever after ureteroscopic lithotripsy.

\begin{tabular}{cccc}
\hline Risk Factors & $p$ Value & Odds Ratio & 95\% CI \\
\hline Body mass index & 0.042 & 0.903 & $0.819-0.996$ \\
Stone location & 0.053 & 2.412 & $0.990-5.873$ \\
Gender & 0.068 & 0.495 & $0.232-1.054$ \\
CRP & 0.089 & 1.094 & $0.986-1.214$ \\
Age & 0.115 & 0.530 & $0.240-1.167$ \\
Indwelling ureter stent before surgery & 0.200 & 1.018 & $0.991-1.045$ \\
Antibiotics use before surgery & 0.317 & 0.601 & $0.222-1.628$ \\
\hline
\end{tabular}

CI, confidence interval; CRP, C-reactive protein.

\section{Discussion}

POF is the most common complication after endoscopic procedures of the urinary tract [14]. To date, many studies have reported the risk factors of POF after URS or URSL [15-18]. In multivariate analyses, POF after URS or URLS has been shown to be associated with longer operative duration $[5,15,16]$, female patients $[15,17,18]$, preoperative bacteriuria or pyelonephritis [16-18], and infectious stones [16,18]. However, several studies have not been able to identify predictive factors for infectious complications after URS or URSL $[11,13]$. Chugh et al. reported that antibiotic prophylaxis was practiced in most of the included studies, which reduced the risk of infection [19]. Infectious complications vary and include fever, urinary tract infection (UTI), pyelonephritis, systemic inflammatory response syndrome, and urosepsis [19]. Therefore, antibiotics should be tailored to local resistance profiles, which tend to reduce the rates of infection and urosepsis [20]. In addition, several factors, such as preoperative UTI, higher Charlson comorbidity index, elderly or female patients, indwelling ureter stent, operation duration, and patients with high BMI, may be associated with POF [19]. In addition, URSL has many potential causes, including ureteral obstruction by stone fragments, UTI, intraoperative backflow and extravasation of the urine due to prolonged high-pressure irrigation, intraoperative and postoperative bleeding, and postoperative backflow of the urine in the bladder and ureter due to poor drainage via the catheter [21]. In a study by Sugihara et al., severe adverse events were associated with longer operative times and lower hospital volumes [15]. In our study, preoperative bacteriuria, administration of antibiotics before surgery, and C-reactive protein (CRP) levels were not associated with POF in multivariate analysis. Further, the operation duration in this study was similar to that reported in previous studies $[5,13,17-19]$. Therefore, intraoperative backflow or high-pressure irrigation may be a potential risk factor for POF after URSL.

In our study, low BMI was a predictive factor for POF after URSL. To our knowledge, the association between POF after URSL and BMI is unclear. Obesity is a risk factor for the development of kidney disease [22]. In a previous study, the urinary excretion of risk factors for stone formation and inhibitory substances was significantly higher in patients with overweight and obesity than in patients with normal weight and underweight [22]. Vale et al. reported the most (60.6\%) patients who were overweight or obese and that an increase in BMI was associated with higher urinary calcium excretion [23]. Moreover, a recent systematic review and meta-analysis has demonstrated a significant association between urolithiasis and metabolic syndrome [24]. However, patients with overweight or obesity did not demonstrate an increased risk according to mortality from sepsis in another study [25]. In a retrospective study using the CERNER ${ }^{\mathrm{TM}}$ HealthFacts electronic health record database, Pepper et al. identified 55,038 patients with sepsis between 2009 and 2015 [26]. The BMI groups were underweight (BMI: $<18.5 \mathrm{~kg} / \mathrm{m}^{2}$ ), normal weight (BMI: 18.5-24.9 kg/m²), overweight (BMI: $25.0-29.9 \mathrm{~kg} / \mathrm{m}^{2}$ ), and obese (BMI: $>30 \mathrm{~kg} / \mathrm{m}^{2}$ ) [26]. Using multivariate analysis, the adjusted odds ratio of short-term mortality (death or hospice) was 1.62 for an underweight BMI, 0.73 for an overweight BMI, and 0.61 for an obese BMI [26]. Similarly, the 28-day mortality risk was 1.8-fold higher in the underweight group than in the normal weight group in the overall cohort and 2.9-fold higher in the sepsis sub-cohort [26]. In addition, patients who were underweight had a longer intensive 
care unit length of stay, increased need for mechanical ventilation support, and a higher frequency of fluid overload [25]. Morokuma et al. have suggested that low BMI may be a risk factor of POF after URSL, despite the small number of patients enrolled in this study [27]. Therefore, patients with a low BMI may develop POF easily after URS or URSL.

Our study has several limitations. First, this was a retrospective study that was conducted using multicenter data. Therefore, this study has an inherent potential for bias, with therapeutic variations among these institutions. Second, a relatively small number of patients were enrolled, and patients with bilateral stones were excluded from this study. Finally, not all patients were examined for urine culture and neutrophil and lymphocyte counts before surgery and analysis of stone components after surgery.

\section{Conclusions}

POF is the most common complication after URS or URSL. In this study, it was not necessary to administer antibiotic prophylaxis, even if the patients had bacteriuria before surgery. In addition, a low BMI was significantly associated with POF after URS or URSL. Therefore, patients with a low BMI need to be more careful with POF such as urosepsis during URS or URSL.

Author Contributions: K.S., T.I., T.T., S.F., D.K., M.T. (Manabu Takai), K.I., K.N. and T.K. contributed to study conception and design. H.U., M.T. (Masayoshi Tamaki) and H.K. supervised. K.S. drafted the manuscript, which was revised by T.K. All authors have read and agreed to the published version of the manuscript.

Funding: This research did not receive any specific grant from funding agencies in the public, commercial, or not-for-profit sectors.

Institutional Review Board Statement: All procedures performed in studies involving human participants were in accordance with the ethical standards of the institutional and/or national research committee and with the 1964 Helsinki Declaration and its later amendments or comparable ethical standards. The study was approved by the institutional review boards of Chuno Kosei Hospital (number: R3-1) and Gifu Municipal Hospital (number: 707).

Informed Consent Statement: The need for informed consent was waived because this was a retrospective cohort study.

Data Availability Statement: Data and materials are provided in this paper.

Conflicts of Interest: The authors declare that they have no competing interests.

\section{References}

1. Scales, C.D., Jr.; Smith, A.C.; Hanley, J.M.; Saigal, C.S. Urologic Diseases in America Project. Prevalence of kidney stones in the United States. Eur. Urol. 2012, 62, 160-165. [CrossRef]

2. Inoue, T.; Okada, S.; Hamamoto, S.; Yoshida, T.; Matsuda, T. Current trends and pitfalls in endoscopic treatment of urolithiasis. Int. J. Urol. 2017, 25, 121-133. [CrossRef]

3. Yasui, T.; Iguchi, M.; Suzuki, S.; Okada, A.; Itoh, Y.; Tozawa, K.; Kohri, K. Prevalence and epidemiologic characteristics of lower urinary tract stones in Japan. Urology 2008, 72, 1001-1005. [CrossRef]

4. Yasui, T.; Iguchi, M.; Suzuki, S.; Kohri, K. Prevalence and epidemiological characteristics of urolithiasis in Japan: National trends between 1965 and 2005. Urology 2008, 71, 209-213. [CrossRef]

5. Ozgor, F.; Sahan, M.; Cubuk, A.; Ortac, M.; Ayranci, A.; Sarilar, O. Factors affecting infectious complications following flexible ureterorenoscopy. Urolithiasis 2019, 47, 481-486. [CrossRef] [PubMed]

6. Bhojani, N.; Miller, L.E.; Bhattacharyya, S.; Cutone, B.; Chew, B.H. Risk Factors for Urosepsis After Ureteroscopy for Stone Disease: A Systematic Review with Meta-Analysis. J. Endourol. 2021, 35, 991-1000. [CrossRef]

7. Knoll, T.; Jessen, J.P.; Honeck, P.; Wendt-Nordahl, G. Flexible ureterorenoscopy versus miniaturized PNL for solitary renal calculi of 10-30 mm size. World J. Urol. 2011, 29, 755-759. [CrossRef] [PubMed]

8. De la Rosette, J.; Denstedt, J.; Geavlete, P.; Keeley, F.; Matsuda, T.; Pearle, M.; Preminger, G.; Traxer, O.; CROES URS Study Group. The clinical research office of the endourological society ureteroscopy global study: Indications, complications, and outcomes in 11,885 patients. J. Endourol. 2014, 28, 131-139. [CrossRef]

9. Perez Castro, E.; Osther, P.J.; Jinga, V.; Razvi, H.; Stravodimos, K.G.; Parikh, K.; Kural, A.R.; de la Rosette, J.J.; CROES Ureteroscopy Global Study Group. Differences in ureteroscopic stone treatment and outcomes for distal, mid-, proximal, or multiple ureteral 
locations: The Clinical Research Office of the Endourological Society ureteroscopy global study. Eur. Urol. 2014, 66, 102-109. [CrossRef] [PubMed]

10. De, S.; Autorino, R.; Kim, F.J.; Zargar, H.; Laydner, H.; Balsamo, R.; Torricelli, F.C.; Di Palma, C.; Molina, W.R.; Monga, M.; et al. Percutaneous nephrolithotomy versus retrograde intrarenal surgery: A systematic review and meta-analysis. Eur. Urol. 2015, 67, 125-137. [CrossRef]

11. Cindolo, L.; Castellan, P.; Scoffone, C.M.; Cracco, C.M.; Celia, A.; Paccaduscio, A.; Schips, L.; Proietti, S.; Breda, A.; Giusti, G. Mortality and flexible ureteroscopy: Analysis of six cases. World J. Urol. 2016, 34, 305-310. [CrossRef] [PubMed]

12. Sharma, K.; Sankhwar, S.N.; Goel, A.; Singh, V.; Sharma, P.; Garg, Y. Factors predicting infectious complications following percutaneous nephrolithotomy. Urol. Ann. 2016, 8, 434-438. [CrossRef]

13. Berardinelli, F.; De Francesco, P.; Marchioni, M.; Cera, N.; Proietti, S.; Hennessey, D.; Dalpiaz, O.; Cracco, C.; Scoffone, C.; Schips, L.; et al. Infective complications after retrograde intrarenal surgery: A new standardized classification system. Int. Urol. Nephrol. 2016, 48, 1757-1762. [CrossRef] [PubMed]

14. Kim, J.W.; Lee, Y.J.; Chung, J.W.; Ha, Y.S.; Lee, J.N.; Yoo, E.S.; Kwon, T.G.; Kim, B.S. Clinical characteristics of postoperative febrile urinary tract infections after ureteroscopic lithotripsy. Investig. Clin. Urol. 2018, 59, 335-341. [CrossRef]

15. Sugihara, T.; Yasunaga, H.; Horiguchi, H.; Nishimatsu, H.; Kume, H.; Ohe, K.; Matsuda, S.; Fushimi, K.; Homma, Y. A nomogram predicting severe adverse events after ureteroscopic lithotripsy: 12372 patients in a Japanese national series. BJU Int. 2013, 111, 459-466. [CrossRef]

16. Fan, S.; Gong, B.; Hao, Z.; Zhang, L.; Zhou, J.; Zhang, Y.; Liang, C. Risk factors of infectious complications following flexible ureteroscope with a holmium laser: A retrospective study. Int. J. Clin. Exp. Med. 2015, 8, 11252-11259.

17. Yoshida, S.; Takazawa, R.; Uchida, Y.; Kohno, Y.; Waseda, Y.; Tsujii, T. The significance of intraoperative renal pelvic urine and stone cultures for patients at a high risk of post-ureteroscopy systemic inflammatory response syndrome. Urolithiasis 2019, 47, 533-540. [CrossRef]

18. Uchida, Y.; Takazawa, R.; Kitayama, S.; Tsujii, T. Predictive risk factors for systemic inflammatory response syndrome following ureteroscopic laser lithotripsy. Urolithiasis 2018, 46, 375-381. [CrossRef]

19. Chugh, S.; Pietropaolo, A.; Montanari, E.; Sarica, K.; Somani, B.K. Predictors of urinary infections and urosepsis after ureteroscopy for stone disease: A systematic review from EAU section of urolithiasis (EULIS). Curr. Urol. Rep. 2020, 21, 16. [CrossRef] [PubMed]

20. Zisman, A.; Badaan, S.; Kastin, A.; Kravtsov, A.; Amiel, G.E.; Mullerad, M. Tailoring antibiotic prophylaxis for ureteroscopic procedures based on local resistance profiles may lead to reduced rates of infections and urosepsis. Urol. Int. 2020, 104, 106-112 [CrossRef]

21. Doizi, S.; Traxer, O. Flexible ureteroscopy: Technique, tips and tricks. Urolithiasis 2018, 46, 47-58. [CrossRef] [PubMed]

22. Trinchieri, A.; Croppi, E.; Montanari, E. Obesity and urolithiasis: Evidence of regional influences. Urolithiasis 2017, 45, 271-278. [CrossRef] [PubMed]

23. Vale, L.; Ribeiro, A.M.; Costa, D.; Morgado, A.; Antunes-Lopes, T.; Dinis, P.; Silva, C.; Pacheco-Figueiredo, L. Metabolic evaluation in urolithiasis-study of the prevalence of metabolic abnormalities in a tertiary centre. Cent. Eur. J. Urol. 2020, 73, 55-61.

24. Besiroglu, H.; Otunctemur, A.; Ozbek, E. The metabolic syndrome and urolithiasis: A systematic review and meta-analysis. Ren Fail. 2015, 37, 1-6. [CrossRef]

25. Ayalon, I.; Woo, J.G.; Basu, R.K.; Kaddourah, A.; Goldstein, S.L.; Kaplam, J.M.; AWARE Investigators. Weight as a risk factor for mortality in critically ill patients. Pediatrics 2020, 146, e20192829. [CrossRef]

26. Pepper, D.J.; Demirkale, C.Y.; Sun, J.; Rhee, C.; Fram, D.; Eichacker, P.; Klompas, M.; Suffredini, A.F.; Kadri, S.S. Does obesity protect against death in sepsis? A retrospective cohort study of 55,038 adult patients. Crit. Care Med. 2019, 47, 643-650. [CrossRef]

27. Morokuma, F.; Sadashima, E.; Chikamatsu, S.; Nakamura, T.; Hayakawa, Y.; Tokuda, N. The Risk factors of febrile urinary tract infection after ureterorenoscopic lithotripsy. Kobe J. Med. Sci. 2020, 66, E75-E81. 